\title{
Numerical Analysis of the Sensitivity to the Occupant Window Opening of the Yearly Energy Consumptions and of the Indoor Thermal Comfort Conditions in a Series of Reference Cases
}

\author{
Jean Pierre Campana ${ }^{1}$, Gian Luca Morini ${ }^{1}$ \\ ${ }^{1}$ Department of Industrial Engineering (DIN) - Alma Mater Studiorum, Bologna, Italy
}

\begin{abstract}
During the NZEB design phase, accurate dynamic energy simulations are generally carried out, in many cases, neglecting the effect of the occupant behaviour on the energy consumptions. The aim of this work is to investigate the influence of the occupant behaviour (i.e. window openings) on the seasonal energy building performance in order to demonstrate that the occupant can play a significant role, especially for NZEB. Numerical results evidence how the sensitivity of the heating energy demand and comfort conditions on the different design parameters can change dramatically if the occupant behaviour is taken into account within the dynamic energy model of the building.
\end{abstract}

\section{Introduction}

Nowadays, NZEB designers are motivated to individuate the best combination of envelope features and HVAC characteristics in order to minimize energy consumptions and maximize indoor comfort conditions. In the past decades, several researchers worked on the development of computational models for the building energy performance assessment, leading to very accurate thermal models of buildings. However, in these energy models the occupant behaviour is usually neglected or it is taken into account by means of simple deterministic rules (Degelman 1999). Anyway, both building energy performance and indoor comfort conditions are affected by occupants, able to interact with building and HVAC components (Mahdavi 2011).

Many works demonstrated how, if the occupant behaviour is ignored, a significant discrepancy between measured and predicted energy consumptions can be evidenced. As an example, Turner and Frankel (2008) compared real and predicted (by means of dynamic simulations performed in the design phase) energy consumptions of 62 Leadership in Energy Environmental Design (LEED) buildings by evidencing values of the normalized root-mean-squared difference up to $18 \%$.

Moreover, occupant behaviour is intrinsically affected by uncertainty. In fact, occupant behaviour patterns not only vary between each other, but each occupant does not behave in a deterministic way. In addition, Haldi and Robinson (2010) showed that in common spaces occupants tend to limit their actions compared to occupants in private spaces.
The great discrepancy about the energy performance of buildings in presence of occupant interactions with building (e.g. window operations, blind operations...) and HVAC system (e.g. set-point definition) has been evidenced by several authors. Al-Mumin et al. (2003), analysing the cooling energy demand of 30 residences in Kuwait found that the inner temperature set-point defined by the occupant under similar conditions falls within the range $19-25^{\circ} \mathrm{C}$. Another example of the spread of building energy performance results due to the occupant behaviour is given by Li et al. (2007) who measured the cooling energy needs of 25 household of a residential building in Beijing by highlighting how the energy consumptions of identical buildings varied from 0 to $14 \mathrm{kWh} / \mathrm{m}^{2}$ due to the different behaviour evidenced of the occupants.

In the last two decades researchers started to develop models for mimic the occupant behaviour patterns in common and private indoor spaces. As stated by Parys et $a l$. (2011), in offices there are six main group of actions linked to the behavioural modelling of occupants: (i) occupancy pattern (arrival and departure time); (ii) occupant control of shading devices; (iii) occupant control of windows; (iv) occupant control of artificial lighting; (v) occupant control of appliances and (vi) occupant control of thermal environment (e.g. air change ratio, indoor temperature set-point). For each of these group of actions, several models have been proposed without achieving a unique wide accepted model up to now.

The occupant control of windows consists of models able to mimic window opening and closing in a closed space. In fully conditioned buildings, windows are not operable. On the contrary, in buildings not provided by cooling systems, window opening is the simplest solution that occupants can experience in order to obtain summer free cooling. A first model for mimic occupant control of windows was proposed by Warren and Parkins (1984). After this first model, several models have been proposed; among these models, the stochastic Humphreys Adaptive Algorithm proposed by Rijal (2007) represents one of the most successful. This model, validated for natural ventilated building, assumes the indoor and outdoor temperature as the main driving factors for the windows opening. Two years later, Yun et al. (2009), proposed a modification of the Humphreys Adaptive Algorithm in which different probabilities of window openings are defined depending on the typology of users (subdivided in active, medium and passive users). 
Recently, Karjalainen (2016) introduced the concept of "robust design solutions" as the combination of design parameters for a building able to make the design less sensitive to occupant behaviour. Karjalainen (2016) compared the energy consumptions for heating, cooling and electricity of a building by considering three different user behaviours (i.e. careless, normal and conscious) and two design strategies (ordinary and robust). Results shows that the adoption of a robust design limits the sensitivity of the total energy consumption to the occupant behaviour. Karjalainen (2016) demonstrated that in a specific case, by adopting an ordinary building design the annual energy consumption in presence of conscious occupants can be reduced up to $82 \%$ with respect to the energy consumption obtained in presence of careless occupants. The adoption of strategies for limiting the occupant impact on the energy consumption (robust design) can reduce this difference down to $36 \%$.

These results demonstrate how an effort for the introduction of models able to mimic occupant behaviour in energy simulations is mandatory in order to enable NZEB designers to verify the level of robustness of a building in terms of sensitivity of both energy consumption and indoor conditions by occupant behaviour.

In this paper, by means of a series of dynamic simulations obtained by using ALMABuild (Campana et al., 2017) for a single-zone office, it is evidenced how both energy consumptions and indoor comfort conditions can be influenced in a different way by the main envelope characteristics (i.e. thermal insulation position in the envelope stratigraphy, windows orientation) and HVAC features (i.e. radiator size, typology of control system) if the occupant behaviour is considered or ignored.

\section{Method}

In this section, information about the case study analysed and the behavioural model adopted are provided.

\section{Case Study}

The building considered for this case study is a singlezone office, located in Bologna, Italy. The geometry of the room is represented in Figure 1: the floor is a slab-ongrade of $48 \mathrm{~m}^{2}$ and the roof is horizontal. All the walls are exposed to the outdoor environment and two double pane windows are present. The U-values of the envelope elements are reported in Table 1, whilst constant infiltrations are responsible of a constant air-change rate of $0.3 \mathrm{vol} / \mathrm{h}$.

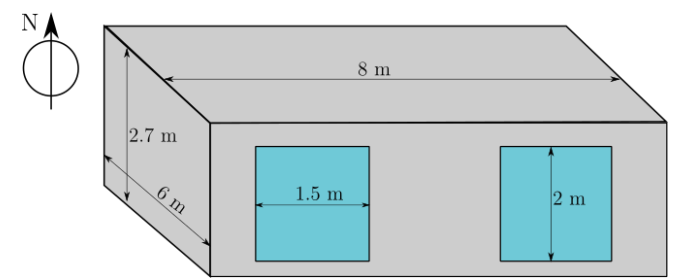

Figure 1-Geometry of the analysed room
Table 1 - U-values [ $\left.\mathrm{W} / \mathrm{m}^{2} \mathrm{~K}\right]$ of envelope elements.

\begin{tabular}{|c|c|}
\hline Elements & U-value \\
\hline External wall & 0.4 \\
\hline Roof & 0.31 \\
\hline Floor & 0.32 \\
\hline Windows & 1.7 \\
\hline
\end{tabular}

No cooling systems are provided to the office; natural ventilation, through windows openings, is the only cooling mechanism available during the summer. The results obtained by the surveys of Larsen and Heiselberg (2008) are used for modelling the air change rate $(\mathrm{ACH})$ due to the window opening as a function of the absolute temperature difference between indoor and outdoor $(\Delta T)$. The air change rate profile for natural ventilation, considering mean values of the wind speed, is represented in Figure 2.

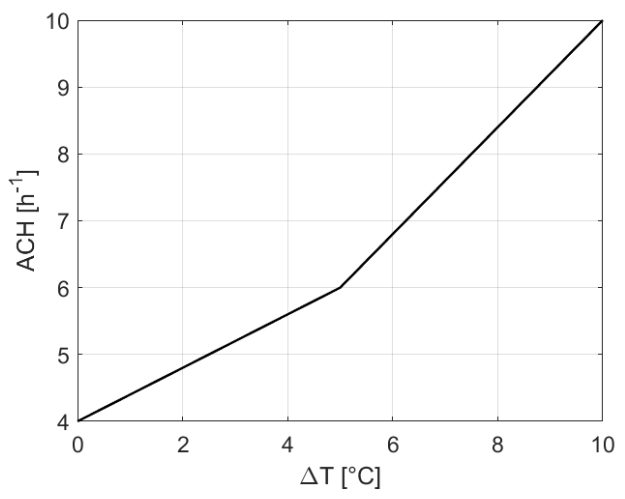

Figure 2 - Air change rate as a function of the absolute temperature difference between indoor and outdoor.

Occupancy is modelled by means of a fixed schedule: occupants are present from 7:00 to 20:00; for the same period, convective and radiative constant internal gains equal to 120 and $80 \mathrm{~W}$ respectively are considered. On the contrary, heating system is activated from 5:00 to 19:00, each day from October 15 to April 15.

Different cases, related to various envelope and heating system configurations, are considered in this work. More in detail, the two windows are both inserted in the South Wall (label $S$ ), as represented in Figure 1, or in the East and West Walls (label $E W$ ). Moreover, the thermal insulation layer of the external walls and roof can be placed in the external (label $O$ ) or in the internal (label $I$ ) layer. In addition, effect of different radiator sizing are explored: label 80 refers to radiator, whose characteristic are reported in Table 2; the emitter is designed by imposing a nominal inlet water temperature of $80{ }^{\circ} \mathrm{C}$ and a temperature difference between inlet and outlet of $20 \mathrm{~K}$, whereas a nominal inlet water temperature of $70{ }^{\circ} \mathrm{C}$ and a temperature difference of $10 \mathrm{~K}$ is considered for cases labelled 70 .

Table 2 - Main characteristics of a radiator element

\begin{tabular}{|c|c|}
\hline Nominal power [W] & 91.1 \\
\hline Exponent [-] & 1.31 \\
\hline Water content [1] & 0.74 \\
\hline Weight [kg] & 5.4 \\
\hline
\end{tabular}


Finally, three different control strategies are considered: in cases labelled $D B$ the heating control system is composed by a temperature controller with a dead band of $\pm 1 \mathrm{~K}$ and a set-point temperature of $23{ }^{\circ} \mathrm{C}$ (office in indoor environment category 2 in agreement with $\mathrm{EN}$ 15251 (2007)); if a weather compensation is adopted (reducing the inlet water temperature according to the external air temperature, as represented in Figure 3) the label is $W C$, whilst $V$ refers to cases in which a thermostatic valve is coupled to the emitter.

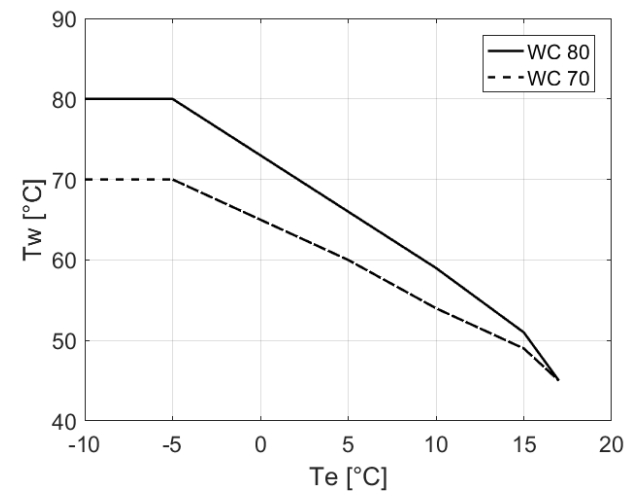

Figure 3 - Inlet water temperature (Tw) as a function of the external temperature (Te) for the two radiator sizes (labels 80 and 70) when the weather compensation is adopted.

\section{Occupant behaviour model}

In this work, for sake of simplicity, in the single-zone office only the occupant behaviour related to the windows opening is taken into account, neglecting the occupant control on blinds, indoor temperature, appliances, artificial lighting and considering a fixed occupancy schedule. A stochastic model has been implemented in ALMABuild, an open Simulink blockset for the building energy simulations (Campana et al., 2017). More in detail, the stochastic Humphreys Adaptive Algorithm (Rijal, 2007) has been used for the modelling of occupant windows opening. This algorithm has been developed from field surveys conducted in 15 UK offices. The starting point of this algorithm is the evaluation of the comfort conditions sensed by the occupant. Adaptive comfort temperature $\left(T_{\text {comf }}\right)$ is introduced and estimated as a function of the running mean outdoor temperature $\left(T_{r m o}\right)$, defined by EN 15251, as follows:

$$
\left\{\begin{array}{l}
T_{\text {comf }}=0.33 T_{r m o}+18.8 \text { if } T_{r m o}>10^{\circ} \mathrm{C} \\
T_{\text {comf }}=0.09 T_{r m o}+22.6 \text { if } T_{r m o} \leq 10^{\circ} \mathrm{C}
\end{array}\right.
$$

The occupant is stated to sense comfort conditions if the operative temperature is within the range $\pm 2 \mathrm{~K}$ around the adaptive comfort temperature; otherwise the occupant state is hot (operative temperature higher than $2 \mathrm{~K}$ to the comfort temperature) or cold (temperature under the range). If uncomfortable indoor conditions are sensed by the occupant, the window opening probability $(P)$ is evaluated by means of the following logit function:

$$
\left\{\begin{array}{l}
\operatorname{logit} P=0.171 T_{o p}+0.166 T_{e}-6.4 \\
P=\frac{\exp (\operatorname{logit} P)}{(1+\exp (\operatorname{logit} P))}
\end{array}\right.
$$

Then, the window opening probability is compared to a random number within the range $0-1$. In the case of hot occupant state and closed window, if the window opening probability is greater than the random number, the window is opened by the occupant. On the contrary, in the case of open window and cold occupant state, if the random number is greater than the window opening probability, the occupant closes the window. It has to be remarked that, in the Humphreys Adaptive Algorithm comfort conditions are evaluated only as a function of the indoor operative temperature, neglecting the effects of air humidity ratio on occupant feelings. Moreover, this algorithm does not depend on the number of occupants. In the simulations presented in this paper, contrary to the Rijal et al. (2007), the Humphreys Adaptive Algorithm is run every 10 minutes.

Heating energy consumptions are evaluated by means of dynamic annual simulations by considering the energy $(E)$ provided by radiators to the office. On the contrary, occupant comfort conditions are estimated by means of the values assumed during the year by the adaptive comfort temperature. More in detail, the comfort time $\left(\tau_{\mathrm{c}}\right)$ is introduced for the evaluation of the comfort conditions during the heating season. The comfort time is defined as the percentage of annual working time in which the occupant feels comfort conditions in the office (i.e. the operative temperature is within the band $\pm 2 \mathrm{~K}$ with respect to the adaptive comfort temperature).

\section{Results}

\section{Energy and Comfort results neglecting the occupant behaviour}

First of all, annual dynamic simulations are performed by ignoring the occupant behaviour, in order to create a baseline for the comparisons. The comfort time obtained for all the cases considered in this work is shown in Figure 4.

In rooms in which the thermal insulation layer is placed on the inner layer (see Figure 4a) the higher comfort time $(81.1 \%)$ is obtained, regardless the radiator sizing and the control system, for windows placed on the South wall. For windows placed on West and East walls $\tau_{c}$ decreases down to $74 \%$. Even in this case, in Figure $4 \mathrm{a}$ it can be noted that the radiator size and the typology of control system affect the comfort time only marginally: the maximum discrepancy between the results is $0.9 \%$ and $0.5 \%$ for different radiators and control system, respectively.

Placing the thermal insulation on the external layer instead of the internal one, an increase of about $10 \%$ of the comfort time is evidenced (see Figure 4b). In fact, if windows are on the South wall, $\tau_{c}$ is around $90 \%$ and in the case of windows in West and East walls the comfort time reaches $84 \%$. Again, the typology of control system 
and the radiator size slightly affect the comfort time: the discrepancies are lower than $0.6 \%$.

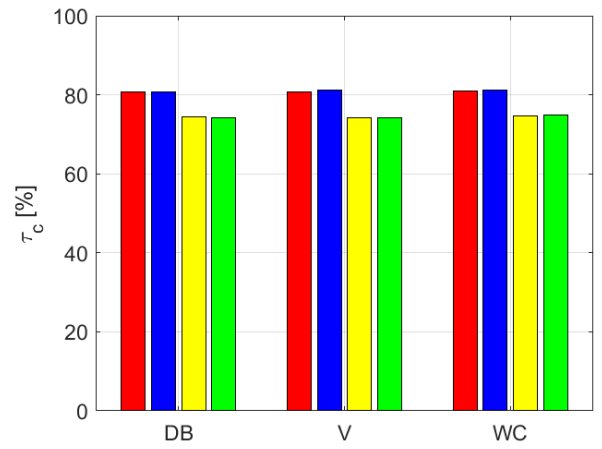

(a)

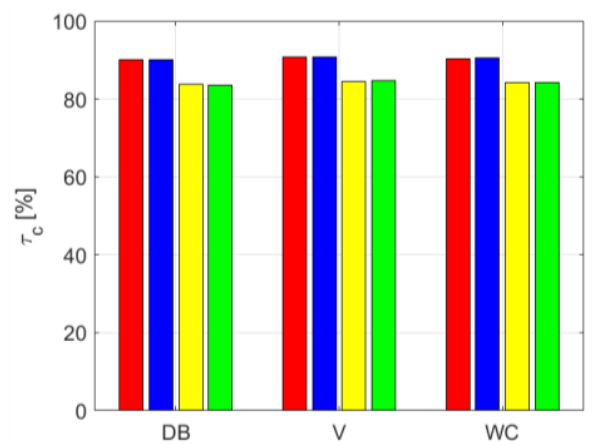

(b)

$\square$ S $80 \square$ S $70 \square$ WE $80 \square$ WE 70

Figure 4: Comfort time for cases with insulation on the inner (a) and outer layer (b).

The analysis of the heating energy demand (see Figure 5) puts in evidence that higher solar gains (obtained with windows South-oriented) determine a reduction of around $12 \%$ of the energy consumption with respect to cases in which windows are East and West-oriented, regardless the thermal insulation position. As for the comfort time, the radiator size does not affect the energy consumptions: discrepancies due to different radiator sizes are lower than $0.9 \%$. On the contrary, the typology of the control system determines a variation in the energy consumptions: the minimum energy needs are obtained adopting the control system based on the thermostatic valves coupled to the radiator. In fact, in the case of dead-band or weather compensation control strategies the heating demand increases of around 7\% compared to the use of the thermostatic valves, in presence of an inner insulation. Dead-band and weather compensation controls lead to similar energy needs: the discrepancies are lower than $1 \%$.

In a room with thermal insulation placed on the external layer (see Figure 5b) the influence of the control strategy is higher for cases $W E$, for which the difference between the maximum (case $W C$ ) and minimum (case $V$ ) result is around the $8 \%$. Moreover, the adoption of the dead-band control leads to a reduction of the energy needs of around $3 \%$ compared to the use of the weather compensation.

The effects of the thermal insulation position depends on the typology of control system: if the dead-band control is adopted, placing the insulation on the external layer instead of the internal one causes an increase of the energy consumption of around 8\%, whereas in the case of adoption of thermostatic valves or weather compensation the increment is around $12 \%$ and $13 \%$ respectively.

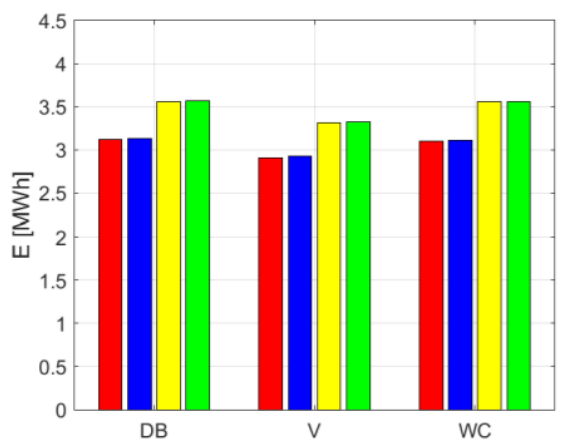

(a)

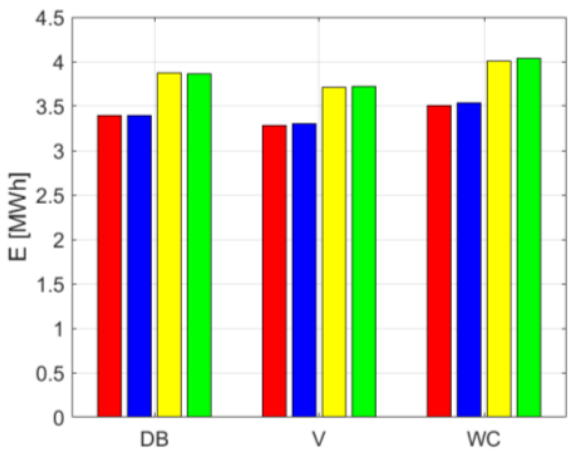

(b)

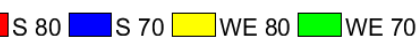

Figure 5: Energy heating demand for cases with insulation on the inner $(a)$ or outer layer $(b)$.

It is possible to summarize these results by observing how the adoption of thermostatic valves on radiators, the presence of windows placed on the South wall and the adoption of a thermal insulation placed on the external envelope layer, represents the best combination in order to obtain low energy consumptions and high comfort conditions.

\section{Energy and Comfort results considering the occupant behaviour}

The evaluation of the impact of the occupant behaviour, related to the window control, on comfort conditions and energy consumptions have been evaluated by repeating the numerical annual simulations for all the cases described in the previous Section. The Humphreys Adaptive Algorithm have been employed. Ten numerical simulations have been performed for each design combination in order to check the distribution of the obtained results due to the stochastic behaviour of the Humphreys algorithm. Typical values of the relative standard deviation of the numerical results in terms of comfort and energy indexes are lower than $0.05 \%$ and $0.6 \%$ respectively.

The analysis of the comfort time $\left(\tau_{c}\right)$ for rooms with insulation placed on the internal layer (see Figure 6a) shows small discrepancies among different configurations: the maximum difference of $\tau_{\mathrm{c}}$ obtained varying the control system is $0.34 \%$, whilst changing the 
radiator sizing leads to discrepancies lower than $0.15 \%$. More significant differences are evidenced modifying the windows position: locating the windows on the South wall determines comfort time around $1.5 \%$ higher than inserting windows in the East and West walls.

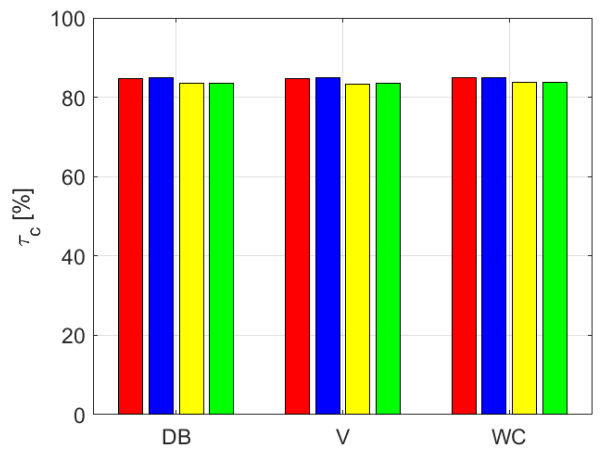

(a)

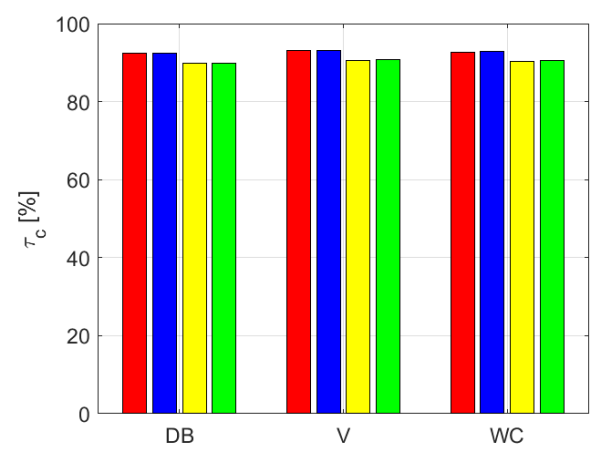

(b)

\section{S $80 \square$ S $70 \square$ WE $80 \square$ WE 70}

Figure 6: Comfort time for cases with insulation on the inner (a) and outer layer (b), considering the occupant behaviour.

Similar conclusions can be assessed referring to a room characterised by insulation placed on the external envelope layer (see Figure 6b). In fact, higher $\tau_{\mathrm{c}}$ are evidenced in the case of windows South-oriented $(+2.5 \%$ with respect to case WE), whereas the radiator sizing does not affect the comfort time (maximum discrepancy is lower than $0.1 \%$ ). A control system based on thermostatic valves guarantees the higher comfort times, whilst the dead-band control leads to comfort time around $1 \%$ lower than those obtained with thermostatic valves. Comparing the results represented in Figure 6 it can be remarked that placing the insulation on the external envelope layer higher comfort times, around $90 \%$, are obtained.

From the results represented in Figure 7, higher heating energy consumptions can be observed for a room with windows East and West-oriented (around +11-12\% compared to the same room with South-oriented windows), regardless the insulation layer position. Moreover, the position of the insulation layer does not affect the performances of the control system based on the thermostatic valves, which guarantees the lower energy consumptions. On the contrary, the dead-band and weather compensation control are influenced by the insulation layer position: if insulation is located in the internal layer, higher energy consumptions are obtained with a dead-band control (around $+12 \%$ compared to the minimum values), whereas for cases $O$ the weather compensation is responsible of the higher consumptions ( $+7 \%$ compared to the lower values).

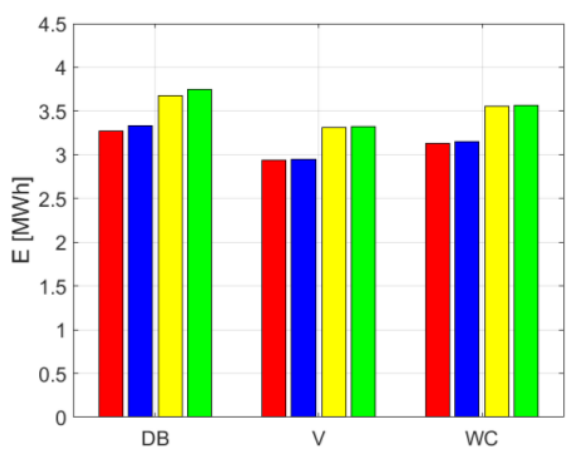

(a)

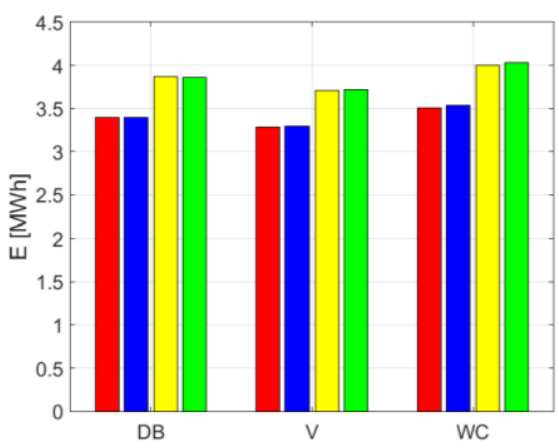

(b)

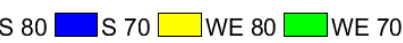

Figure 7: Energy demand for cases with insulation on the inner ( $a$ ) and outer layer $(b)$, considering the occupant behaviour.

The radiator sizing very slightly affects the heating energy consumptions; in fact the discrepancy between cases labelled 80 and cases 70 is lower than $1 \%$ in all the room configurations, except if a dead-band control is adopted in cases $I$, for which the discrepancies are around $2 \%$.

Finally, comparing the results showed in Figure 7, it can be appreciated that moving the insulation from the internal layer to the external one is responsible of an increment of the heating energy demand of around $12 \%$, except for cases DB, for which the increase is only around $3 \%$.

\section{Discussion}

The adoption of the occupant control on windows determines remarkable implications on both annual heating energy consumptions and indoor comfort conditions.

Referring to comfort conditions, higher comfort times are evidenced if the occupant can control the window opening. More in detail, the higher increase of comfort times are observed for a room with windows East and West-oriented and for a room with the insulation layer on the internal side. In fact, under these conditions, frequent overheating conditions (i.e. operative temperature higher more than $2 \mathrm{~K}$ than the adaptive comfort temperature) are observed. If the occupant behaviour is taken into account, 
the overheating time, i.e. the percentage of working time in which overheating conditions appear, can be halved compared to cases in which the occupant behaviour is neglected, as it can be observed by the data shown in Table 3 where the overheating time, averaged for the different HVAC configurations, is reported.

Table 3 -Average overheating time [\%], both considering and neglecting the occupant behaviour.

\begin{tabular}{|c|c|c|c|c|}
\hline & \multicolumn{2}{|c|}{$\begin{array}{c}\text { No } \\
\text { occupant }\end{array}$} & \multicolumn{2}{|c|}{ Occupant } \\
\hline $\begin{array}{c}\text { Window } \\
\text { Exposition\Insulation } \\
\text { position }\end{array}$ & I & O & I & O \\
\hline South & 13.5 & 5.8 & 9.8 & 3 \\
\hline East/West & 19 & 11.7 & 10 & 5.5 \\
\hline
\end{tabular}

The occupant behaviour affects the evaluation of the annual heating energy consumptions. In particular, the window opening due to the occupant determines higher energy consumptions. If the dead-band control is adopted and the thermal insulation is on the internal layer, the window openings due to the occupant determine increments of $5 \%$ and $3.5 \%$ for cases $I D B S 80$ and $I \_D B \_W E \_80$, whilst if bigger radiators are installed, increments on energy consumptions due to the occupant behaviour are higher $(+6.4 \%$ and $+5 \%$ for cases $I \_D B \_S \_70$ and $\left.I \_D B \_W E \_70\right)$.

Moreover, it is interesting to observe that in rooms characterised by windows East and West-oriented and insulation on the internal side (except if the dead-band control is adopted) the energy demand is the same, not depending on the occupant behaviour. This fact is remarked for all the cases in which the insulation layer is on the external side. The reason of the absence of influence on the energy consumptions of the occupant behaviour is that in these cases overheating conditions, which are responsible of the window opening, appear only in summer, when the heating system is off. On the contrary, if the room has South-oriented windows and insulation on the internal layer, the higher solar gains can determine overheating conditions also in the mid-seasons when the heating system is still on, especially if very simple control system (Dead-Band) is adopted.

In conclusion, it can be stated that, in specific room configurations, the occupant behaviour determines better indoor comfort without affecting the energy consumptions.

\section{Sensitivity analysis}

The sensitivity analysis of annual heating energy demand and of comfort time is carried out comparing the results obtained for the different room configurations, both considering and neglecting the occupant behaviour. The sensitivity analysis of the results is related to the robustness assessment of the design configurations proposed in the design phase.

The sensitivity of both energy consumptions and comfort conditions to the different room configurations analysed in the previous Section is evaluated as:

$$
S_{R x}=\frac{\max _{x} R_{x}-\min _{x} R_{x}}{\max _{x} R_{x}}
$$

where $S_{R, x}$ is the sensitivity to the room parameter $x$, (i.e. insulation position (ins), windows orientation (or), radiator size ( $\mathrm{dim}$ ) and control system ( $\mathrm{reg}$ )) of the output $R$, (i.e. the comfort time or the annual energy demand).

Focusing on a specific room parameter, as an example the insulation position, several different room configurations exist and for each of them the sensitivity to the fixed room parameter (i.e. the insulation position in this example) can be evaluated. For this reason, in Figure 8 the mean value of the sensitivity to the room parameters is reported, together with error bars which evidence the minimum and maximum sensitivity values obtained in simulations.

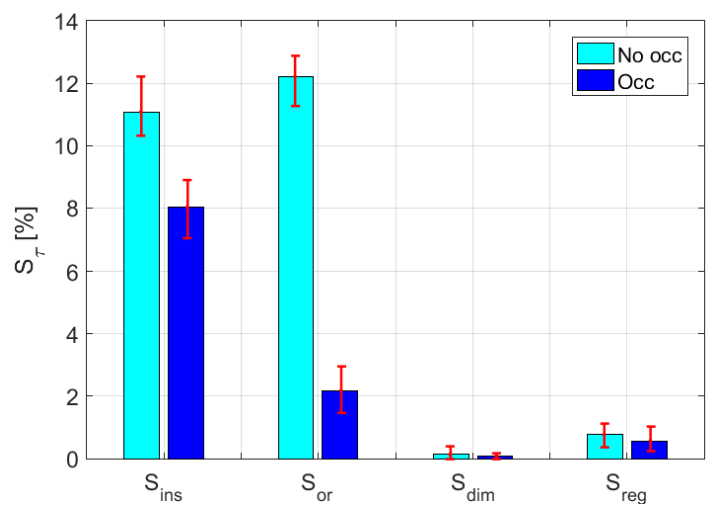

(a)

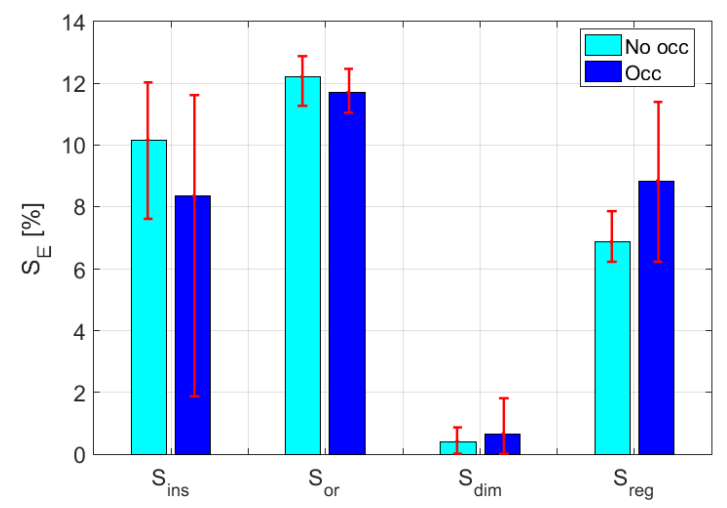

(b)

Figure 8: Mean sensitivity of the comfort time (a) and heating energy demand (b). The red error bars highlights the maximum and minimum values.

Referring to the sensitivity of comfort conditions to the room parameters, represented in Figure 8a, a significant reduction of the sensitivity of the results is evidenced if the occupant behaviour is introduced in the numerical simulation. This is an important consequence of the possibility of the occupant to interact with the room. More in detail, if the occupant behaviour is neglected, comfort conditions are more sensitive to the position of the insulation layer in the envelope stratigraphy and to the windows orientation (the mean value of sensitivity is around $11 \%$ and $12 \%$, respectively). On the contrary, comfort conditions are not significantly affected by the radiator size and the typology of control, in fact the sensitivity to these parameters is lower than $1 \%$, if the 
occupant behaviour is neglected. Similar trends are observed if the occupant behaviour is considered: comfort conditions are not affected by the radiator size $\left(S_{\tau, \mathrm{dim}}\right)$ and typology of control system $\left(\mathrm{S}_{\tau, \mathrm{reg}}\right)$ : the mean sensitivity value to the control system is lower than $0.5 \%$, whilst the $\mathrm{S}_{\tau, \mathrm{dim}}$ tends to zero $(0.08 \%)$. Higher sensitivity values are observed for the insulation position and windows orientations. In particular, it can be noted that $S_{\text {or }}$ is reduced more than $83 \%$ with respect to the value obtained neglecting the occupant behaviour.

The heating demand sensitivity is shown in Figure 8b. In this case, an opposite effect of the occupant behaviour can be evidenced. In fact, referring to the insulation position and the windows orientation, the occupant behaviour determines a reduction of the sensitivity. On the contrary, the sensitivity of heating demand to the radiator size and the control system typology is higher if the occupant behaviour is taken into account.

More in detail, neglecting the occupant behaviour, the highest sensitivity of the energy demand is observed for windows orientation (around 12\%), followed by the insulation position $\left(\mathrm{S}_{\mathrm{E}, \text { ins }}=10 \%\right)$ and by the control system typology $\left(\mathrm{S}_{\mathrm{E}, \mathrm{reg}}\right.$ around $\left.9 \%\right)$. As for comfort conditions, the sensitivity to radiator sizing is very small, lower than $0.5 \%$. A small difference between the sensitivity considering and neglecting the occupant behaviour is observed also referring to the windows orientation.

Finally, an increase of the energy demand sensitivity to the control system typology is observed if the occupant behaviour is considered.

It can be assessed that, in this case, the presence of an active occupant in the room is responsible of an increase of the robustness of the room configurations, with respect to the annual heating energy demand and the indoor comfort conditions.

\section{Conclusion}

In this paper, the effect of the occupant behaviour, related to the window openings, on the indoor comfort conditions and on the heating energy consumptions of an office has been studied by using ALMABuild. The window opening has been modelled adopting the Humphreys Adaptive Algorithm. Four design room parameters have been varied: (i) the position of the insulation layer of the external walls; (ii) the window orientation, (iii) the radiator sizing and (iv) the control system typology. The sensitivity of annual energy demand and indoor comfort conditions to these four design parameters have been investigated both considering or not the occupant presence.

The main results of this work can be summarized as follows:

- higher annual percentage of comfort time can be obtained by taking into account the action of the occupant on the windows since the window opening can strongly reduce the summer overheating;

- the radiator sizing does not affect in a significant way neither the energy consumptions nor the indoor comfort conditions, both neglecting and considering the occupant behaviour;

- the position of the insulation layer on the external side instead of the internal one leads to higher annual percentage of comfort time;

- if the window opening is considered, a slight increment of the annual heating energy demand is observed with respect to the case in which this action is ignored, except in the room with thermal insulation on the external envelope layer;

- the adoption of thermostatic valves coupled to radiators provides the lower energy consumptions among the different control system typology;

- the sensitivity of comfort conditions on the room design parameters is strongly affected by the occupant interaction with windows: the window opening determines a reduction of sensitivity;

- the window opening due to occupant actions reduces the sensitivity of the heating energy demand on the insulation position and window orientation, but it increases the sensitivity to the control system typology.

The results presented in this paper highlight that, for an accurate prediction of the comfort and energy conditions in a building, it becomes mandatory to take into account the occupant behaviour in a realistic way in the numerical models. However, the adopted model has some limitation in the description of the occupant interactions with windows. As an example, the adopted approach does not depend on the number of occupants, even if it is recognized that occupants modify their behaviour if they share the same spaces. For this reason, the development of more precise models able to simulate in a realistic way the occupant interaction with building and HVAC systems must be strongly encouraged.

\section{References}

Al-Mumin A., Khattab O. and Sridhar G. (2003). Occupants' behavior and activity patterns influencing the energy consumption in the Kuwaiti residences. Energy and Buildings, vol. 35.6, 549-559.

Campana J.P., Magni M., Dongellini M., Morini G.L. (2017). The benchmark of a new SIMULINK library for thermal dynamic simulation of buildings. Proceedings from Building Simulation Applications 2017. Bolzano (Italy), 8-10/02/2017.

CEN. (2007). Indoor environmental input parameters for design and assessment of energy performance of buildings addressing indoor air quality, thermal environment, lighting and acoustics (EN 15251).

Degelman L. (1999). A model for simulation of daylight and occupancy sensor as an energy control strategy for office buildings. Proceedings of Building Simulation 99. Kyoto (Japan), 13-15/09/1999.

Haldi F. and Robinson D. (2010). Adaptive actions on shading devices in response to local visual stimuli. 
Journal of Building Performance Simulation, 3.2, 135-153.

Karjalainen S. (2016). Should we design buildings that are less sensitive to occupant behaviour? A simulation study of effects of behaviour and design on office energy consumption. Energy Efficiency 9, 1257-1270.

Larsen T.S. and Heiselberg P. (2008). Single-sided natural ventilation driven by wind pressure and temperature difference. Energy and Buildings 40.6, 1031-1040.

Li Z.-J., Jiang Y. and Wei Q-P. (2007). Survey on energy consumption of air conditioning in summer in a residential building in Beijing. Journal of heating ventilation and air conditioning 37.4, 46-51.

Mahdavi A. (2011). People in Building Performance Simulation. In Hensen, J.L.M., Lamberts R. Building Performance Simulation for Design and Operation. Routledge. London (UK).

Parys W., Saelens D., Hens H. (2011). Coupling of dynamic building simulation with stochastic modelling of occupant behaviour in offices - a reviewbased integrated methodology. Journal of Building Performance Simulation 4.4, 339-358.

Rijal H.B., Tuohy P., Humphreys M.A., Nicol J.F., Samuel A., Clarke J. (2007). Using results from field surveys to predict the effect of open windows on thermal comfort and energy use in buildings. Energy and Buildings 39, 823-836.

Turner C., Frankel M. (2008). Energy performance of LEED for new construction buildings. New Buildings Insitute 4, 1-42.

Warren P., Parkins L. 1984. Window-opening behaviour in office buildings. ASHRAE Transactions 90, 10561076.

Yun G., Tuohy P., Steemers K. (2009). Thermal performance of naturally ventilated building using a combined algorithm of probabilistic occupant behaviour and de-terministic heat and mass balance models. Energy and Buildings 41, 489-499. 